\title{
The Prevalence of Myopia and Factors Associated with It Among Secondary School Children in Rural Vietnam
}

\author{
Ho Duc Hung (D) \\ Duong Dinh Chinh ${ }^{2}$ \\ Pham Van $\operatorname{Tan}^{3}$ \\ Nguyen Viet Duong' \\ Nguyen Quoc Anh ${ }^{3}$ \\ Nguyen Huu Le ${ }^{4}$ \\ Ho Xuan Tuan (ID ${ }^{5}$ \\ Nguyen Tuan Anh (D) ${ }^{6}$ \\ Nguyen Thi Thuy Duong ${ }^{7}$ \\ Vu Duy Kien (iD) 8 \\ 'Quynh Lap National Leprosy \\ Dermatology Hospital, Hoang Mai Town, \\ Nghe An, Vietnam; ${ }^{2} \mathrm{Nghe}$ An \\ Department of Health, Vinh City, Nghe \\ An, Vietnam; ${ }^{3}$ Vietnam National Eye \\ Hospital, Hanoi, Vietnam; ${ }^{4}$ Nghe An Eye \\ Hospital, Vinh City, Nghe An, Vietnam; \\ ${ }^{5}$ School of Medicine and Pharmacy, The \\ University of Da Nang, Da Nang City, \\ Vietnam; ${ }^{6} \mathrm{Hanoi}$ Medical University, \\ Hanoi, Vietnam; ${ }^{7}$ National Institute of \\ Hygiene and Epidemiology, Hanoi, \\ Vietnam; ${ }^{8}$ OnCare Medical Technology \\ Company Limited, Hanoi, Vietnam
}

This article was published in the following Dove Press journal: Clinical Ophthalmology

Purpose: To assess the prevalence of myopia and associated factors among secondary school children in a rural area of Vietnam.

Methods: A school-based cross-sectional study of children in grades six to nine was conducted in four secondary schools in Hoang Mai town, Nghe An Province, Vietnam, during December 2018 and January 2019. The status of myopia was defined as a spherical equivalent objective refractive error of $-0.50 \mathrm{D}$ or worse in either eye. A case-control study was conducted to explore factors associated with myopia, where children with myopia were considered to be cases, and children without myopia were considered to be controls. Factors associated with myopia were analyzed using univariate and multivariate logistic regression. Results: The prevalence of myopia among secondary school children was $14.2 \%$ (95\% CI: $12.7-15.7 \%$ ) and tended to increase with grade, from $10.5 \%$ in grade six to $17.7 \%$ in grade nine. Myopia prevalence in girls was significantly higher than in boys. Factors associated with myopia were a mother with a college/university education $(\mathrm{OR}=2.5,95 \% \mathrm{CI}=$ $1.2-5.3)$, parents who wore spectacles $(\mathrm{OR}=2.0,95 \% \mathrm{CI}=1.1-3.8)$, distance from near work $(\mathrm{OR}=5.2,95 \% \mathrm{CI}=3.5-7.9)$, and taking breaks after 30 minutes of continued reading $(\mathrm{OR}=1.6,95 \% \mathrm{CI}=1.1-2.5)$. However, there were inverse associations with myopia for children belonging to the wealthiest households $(\mathrm{OR}=0.2,95 \% \mathrm{CI}=0.1-0.5)$ and time spent performing outdoor activities $(\mathrm{OR}=0.6,95 \% \mathrm{CI}=0.4-0.9)$.

Conclusion: Our study showed that the prevalence of myopia is considerable among secondary children in rural areas of Vietnam. The prevalence of myopia tended to increase among children in higher grade levels. Thus, appropriate interventions should be developed and conducted to deal with the issue of school-age myopia.

Keywords: myopia, vision impairment, prevalence, secondary school children, rural, Vietnam

\section{Introduction}

Myopia is considered to be a major global public health issue because, if not fully corrected (uncorrected or under-corrected myopia), myopia contributes to major cause of visual impairment. ${ }^{1}$ Moreover, high myopia is associated with other progressive eye disabilities including retinal detachment, glaucoma, cataract, optic disk changes, and maculopathy. ${ }^{2,3}$ As such, uncorrected myopia has an enormous impact on society in relation to education and the economy. ${ }^{4,5}$ The prevalence of myopia varies widely according to the region in the world, such that relatively low prevalence was reported in Africa, whereas higher prevalence was reported in Asia. ${ }^{6}$ Myopia is considered an
Correspondence: Ho Duc Hung Quynh Lap National Leprosy Dermatology Hospital, Quynh Thien Ward, Hoang Mai, Nghe An, Vietnam Tel $+849 \mid 228785$ I

Email hoduchung0905@gmail.com 
epidemic in East and Southeast Asia, where prevalence reaches approximately $80-90 \%$ in young adults in developed countries, such as China, Singapore, Taiwan, Korea and Japan. ${ }^{1}$ Globally, the prevalence of myopia was estimated at $28.3 \%$ in 2010 and is expected to increase to $50 \%$ by $2050 .^{6}$

At present, mechanisms underlying myopia are not clearly understood, although myopia is considered to be caused by interactions between genetic and environmental factors. ${ }^{7,8}$ Genes associated with myopia have been reported, ${ }^{9}$ but the effect of these on the development of myopia was larger among people with higher education. ${ }^{10}$ In children, associated environmental factors include the increased near work and decreased time spent outdoors that often result due to pressure for high educational attainment. ${ }^{8,11,12}$ When myopia occurs at an earlier age, there is a significantly higher probability of developing higher-degree myopia as an adult. ${ }^{3}$ Myopia is also known to be associated with region and community type, as myopia prevalence is likely higher in urban areas than in rural areas. ${ }^{6}$ While not completely understood, urbanization leads to changes in human life that influence time spent performing near-work and outdoor activities that relate to myopia. ${ }^{13,14}$ Given the current knowledge about risk factors for myopia, studies conducted in areas that are rural but in the process of urbanization are needed in order to provide evidence for early myopia intervention for children in the future.

Refractive errors, including myopia, are one of the top public health concerns in Vietnam. ${ }^{15,16}$ To address this issue, the Government of Vietnam approved the Vietnam's National Prevention of Blindness Strategic Plan Towards 2020 and Vision $2030{ }^{16}$ However, relatively few publications related to refractive errors (including myopia) from Vietnam exist, ${ }^{15,17,18}$ including with regards to myopia in school-aged patients in rural areas and especially in areas with incipient urbanization. Given the scarcity of studies in Vietnam that focus on myopia, the development of more effective public health policies is inhibited. Thus, this study aims to assess the prevalence of myopia and associated factors among secondary school children in a rural area in Vietnam.

\section{Methods}

\section{Study Design and Setting}

A school-based cross-sectional study of children in grades six to nine was conducted in four secondary schools in Hoang Mai town, Nghe An Province, Vietnam, during
December 2018 and January 2019. Hoang Mai lies in the North Central Coast region of Vietnam, approximately $200 \mathrm{~km}$ south of Hanoi. The town has a population of 111,000 and the main occupations are fishing, aquaculture, and agriculture, although economic development and urbanization have been rapid in recent years. Hoang Mai town had ten public secondary schools with approximately 7000 children, and there were no private schools. Regular class hours were the same in all schools.

We adapted the Refractive Error Study in Children (RESC) protocol to implement a study that focused solely on myopia. ${ }^{19}$ Based on a cross-sectional study, a casecontrol study was conducted to explore factors associated with myopia, where children with myopia were considered to be cases, and children without myopia were considered to be controls. Each case was matched with a control based on school, class, grade, and sex.

\section{Sample Size and Sampling}

We calculated the sample size according to the RESC protocol method for estimating a population proportion with a specified relative precision. ${ }^{19}$ Before the study, we conducted a pilot study with 100 children in grade six in another un-selected secondary school for evaluation of questionnaires. The sample size was estimated for a gradespecific prevalence of myopia of $15 \%$ (from the pilot study) with a relative precision of 0.3 . We used a 0.05 significance level and an anticipated absenteeism and nonparticipation rate of $10 \%$. Thus, after adjusting for a design effect of two, we estimated a minimum sample size per grade of 484 children, indicating a total required sample size of at least 1936 children. As living conditions in the survey area are relatively homogenous, we did not stratify according to socioeconomic status. Cluster size was equal to the average number of students per class (40 students). According to the estimated minimum sample size, we thus required approximately 48 classes (12 classes per grade). Using the list of ten secondary schools in Hoang Mai, we randomly selected four secondary schools (four of ten schools) for our study. All children in the class were invited to participate in the study. In some cases, we recruited children from other classes of the same grade (starting from the first child in the class register) if the enrollment in a class was less than 40 students in order to satisfy sample size requirements. We applied stratified cluster sampling in our study with four strata per grade. The distribution of students by grade per school was the same, and an equal number of classes were 
selected per grade. The proportion of students in each selected school dictated the number of classes corresponding to that proportion. Therefore, the randomly selected classes in a single grade from a specific school ranged from two to four classes. A total of 2153 children was enrolled in the study, of whom 1987 with complete information were included in the analysis, thus accounting for $28.6 \%$ of children studying in secondary schools in Hoang Mai town.

For the case-control study, we calculated an appropriate sample size using the equation estimating a population proportion with specified relative precision proposed by the World Health Organization. ${ }^{20}$ We used anticipated probabilities of myopic and non-myopic children spending two or more hours outdoors daily of $30 \%$ and $50 \%$, respectively, a significance level of 0.05 , and a relative precision of $30 \%$. As such, the minimum sample size required was 265 children for each case and control group. In this study, we detected 282 myopic children, of which 265 (all with complete information) were enrolled. The selected 265 myopic children were matched with 265 non-myopic children by school, class, grade, and sex.

\section{Variables}

The main outcome variable in this study was myopia status, defined as a spherical equivalent objective refractive error of $-0.50 \mathrm{D}$ or worse in either eye. ${ }^{21}$ The spherical equivalent was estimated as the sum of the sphere power with half of the cylinder power. Independent variables included age (years), sex (male or female), and grade ( six to nine). In addition, other variables included the number of hours that children spent at school or home along with indoor and outdoor activities (such as reading, using computers, watching television, playing sports, etc.). Time spent per activity was estimated and recorded as 0 hours ("not at all"), 0.5 hours (if responded as "less than one hour"), 1 hour, or in hourly increments thereafter. Time spent per activity was estimated for a typical week day and weekend day. Six days per week were considered to be week days (Monday through Saturday), so values for typical week day activity times were multiplied by six and added to weekend hours to estimate total weekly times. Other variables relating to reading behaviors were physical distance from near work $(\geq 30 \mathrm{~cm}$ or $<30 \mathrm{~cm}$ ) and the occurrence of breaks after 30 minutes of continuous reading (yes or no). In addition, parental data, including the mother's educational attainment (primary school or less, secondary school, high school, or college/university), parental spectacle use, and household durable assets (as an estimation of household socioeconomic status).

\section{Data Collection and Ocular Examination}

Class (cluster) enumeration was adapted from the RESC protocol, and data including name, age, sex, parent/guardian name, and contact information were collected. ${ }^{19} \mathrm{We}$ established a data collection team including one experienced ophthalmologist, one refractionist, two ophthalmic nurses, and ten nurses (who conducted interviews). The study team was trained for three days on how to conduct ocular examinations and perform interviews.

Ocular examination included measurements of visual acuity, cycloplegic dilation, cycloplegic autorefraction, and subjective refraction. An ophthalmic nurse measured visual acuity at four meters using a retroilluminated logarithm of the minimum angle of resolution (LogMAR) chart with tumbling E optotypes (Precision Vision, La Salle, IL, USA). Children unable to read the top line at four meters were moved to a distance of one meter. Presenting visual acuity was measured in the right eye and then the left eye for all children. Children presenting with spectacles were measured both with (presenting visual acuity) and without their spectacles (uncorrected visual acuity). Pupillary dilation and cycloplegia were performed when unaided visual acuity measured $6 / 12$ or worse in either eye. Cycloplegia was performed with one drop of topical anesthetic in both eyes (Alcain-proparacaine hydrochloride $0.5 \%$, Alcon, Puurs, Belgium) followed by a two-minute wait to allow ocular surface anesthesia. Two drops of $1 \%$ cyclopentolate (Cyclogyl- cyclopentolate hydrochloride 1\%, Alcon, Puurs, Belgium) were then administered 5 minutes apart per eye. A third drop was administered if a pupillary light reflex was still present after 15 minutes. Full dilation was defined as $6 \mathrm{~mm}$ or greater pupil diameter, and cycloplegia was determined as the absence of pupillary light reflex. Cycloplegic dilation was performed by a refractionist. Cycloplegic refraction was measured with an autorefractor (Grand Seiko 3300K, Shigiya Machinery Works, Hiroshima, Japan) by an ophthalmologist. Further diagnostic assessment or treatment consultations were also provided, and children were referred to the hospital or clinic nearest their home as needed. Subjective refraction was performed by refractionists for children with uncorrected visual acuity of 6/12 or worse in either eye one week later, and children improving with refractive correction were provided with free spectacles. 
The questionnaire from a previous study in Ba RiaVung Tau province in Vietnam was adapted for collecting information about factors associated with myopia (including time that children spent at school or home along with indoor and outdoor activities for a typical week day and weekend day), ${ }^{18}$ and the selected myopic and non-myopic children were interviewed according to these pre-designed questionnaires. The interview team of ten nurses conducted all interviews with children, and also interviewed children's parents or guardians by telephone to collect parental and durable household asset data.

\section{Measurement of Socioeconomic Status}

The wealth asset index was used as a proxy for household socioeconomic status and was constructed using principal component analysis (PCA). ${ }^{22}$ Socioeconomic status was estimated only for those households with children who participated in the case-control study and was derived from reported presence of televisions, telephones, mobile phones, refrigerators, beds, sofas, fans, air conditioners, computers, internet access, washing machines, tractors, motorbikes, cars, and boats. Those variables present at less than $5 \%$ or greater than $95 \%$ were excluded. Factors with eigenvalues greater than 1 were used for extraction in PCA, and varimax (orthogonal) rotation was applied to improve component interpretation. Households were assigned a wealth asset score, ranked from the poorest to the richest, and assigned to wealth asset quintiles.

\section{Data Analysis}

Data entry was completed using EpiData software 3.1 (The EpiData Association, Odense, Denmark) followed by data cleaning and statistical analyses with STATA 14.0 (Stata Corp, College Station, TX, USA). Quantitative data were presented as means and standard deviations, while qualitative data were presented as absolute values and percentages. To compare between two groups, Student's t-tests were used for quantitative variables, and Chi-square tests were used for qualitative variables. Univariate and multivariate logistic regression analyses were conducted to explore potential associations between myopia and relevant factors. Marginal effect analysis was performed on the multivariate logistic regression model to predict the probability of myopia and the marginal effect of the time spent performing outdoor activities weekly. Statistical significance was estimated using p-values less than 0.05 .

\section{Results}

A total of 1987 children aged 12 to 16 years (equivalent to grades six through nine) were included in the study. The nonresponse rate in the cross-sectional study was $7.7 \%$, including children who refused to participate, children absent on the day of the survey, and children whose parents did not sign the informed consent form. Proportions of children between age and school grade groups were nearly equal (range: 24.225.9\%). As the school year in Vietnam begins in September, there was a small difference between the age group and grade proportions; children of ages 12,13,14, and 15 generally studied in grades $6,7,8$, and 9, respectively. Table 1 shows the prevalence and $95 \%$ confidence interval (CI) of myopia among secondary school children according to various factors. The prevalence of myopia among secondary school children was $14.2 \%$ (95\% CI: $12.7-15.7 \%)$ and tended to increase with age, excepting the 16 years old age group, and grade, from $10.5 \%$ in grade six to $17.7 \%$ in grade nine. Myopia prevalence in girls was significantly higher than in boys (16.7\% in girls vs $11.7 \%$ in boys, $\mathrm{p}<0.01)$. The adjusted odds ratio (OR) and 95\% CI for myopia (adjusted for sex) of children in higher grades as compared with children in grade six are shown in Figure 1 . The odds of myopia were higher among the children in grades eight $(\mathrm{OR}=1.7,95 \% \mathrm{CI}=1.2-2.5)$ and nine $(\mathrm{OR}=1.8,95 \% \mathrm{CI}=1.2-2.6)$ as compared those among children in grade six.

Table I Prevalence and 95\% Confidence Intervals of Myopia Among Secondary School Children According to Various Factors

\begin{tabular}{|c|c|c|c|c|}
\hline & \multirow[t]{2}{*}{ n (\%) } & \multicolumn{2}{|c|}{ Myopia } & \multirow[b]{2}{*}{ p-value } \\
\hline & & $\mathbf{N}$ & $\%(95 \% \mathrm{Cl})$ & \\
\hline Overall & 1987 & 282 & $14.2(12.7-15.7)$ & NA \\
\hline \multicolumn{5}{|l|}{ Age (years) } \\
\hline 12 & $487(24.5)$ & 53 & $10.9(8.4-14.0)$ & $<0.01$ \\
\hline 13 & $514(25.8)$ & 59 & II.5 (9.0-14.5) & \\
\hline 14 & $486(24.5)$ & 82 & $16.9(13.8-20.5)$ & \\
\hline 15 & $48 I(24.2)$ & 86 & $17.9(|4.7-2| .6)$ & \\
\hline 16 & $19(1.0)$ & 2 & $10.5(2.5-34.7)$ & \\
\hline \multicolumn{5}{|l|}{ Sex } \\
\hline Female & 987 (49.7) & 165 & $16.7(\mid 4.5-19.2)$ & $<0.01$ \\
\hline Male & $1000(50.3)$ & 117 & II.7 (9.8-13.8) & \\
\hline \multicolumn{5}{|l|}{ Grade } \\
\hline 6 & 514 (25.9) & 54 & $10.5(8.1-13.5)$ & $<0.01$ \\
\hline 7 & $507(25.5)$ & 60 & $11.8(9.3-15.0)$ & \\
\hline 8 & $485(24.4)$ & 83 & I7.I (I4.0-20.7) & \\
\hline 9 & $48 I$ (24.2) & 85 & $17.7(|4.5-2| .3)$ & \\
\hline
\end{tabular}

Abbreviations: $\mathrm{Cl}$, confidence interval; NA, not applicable. 


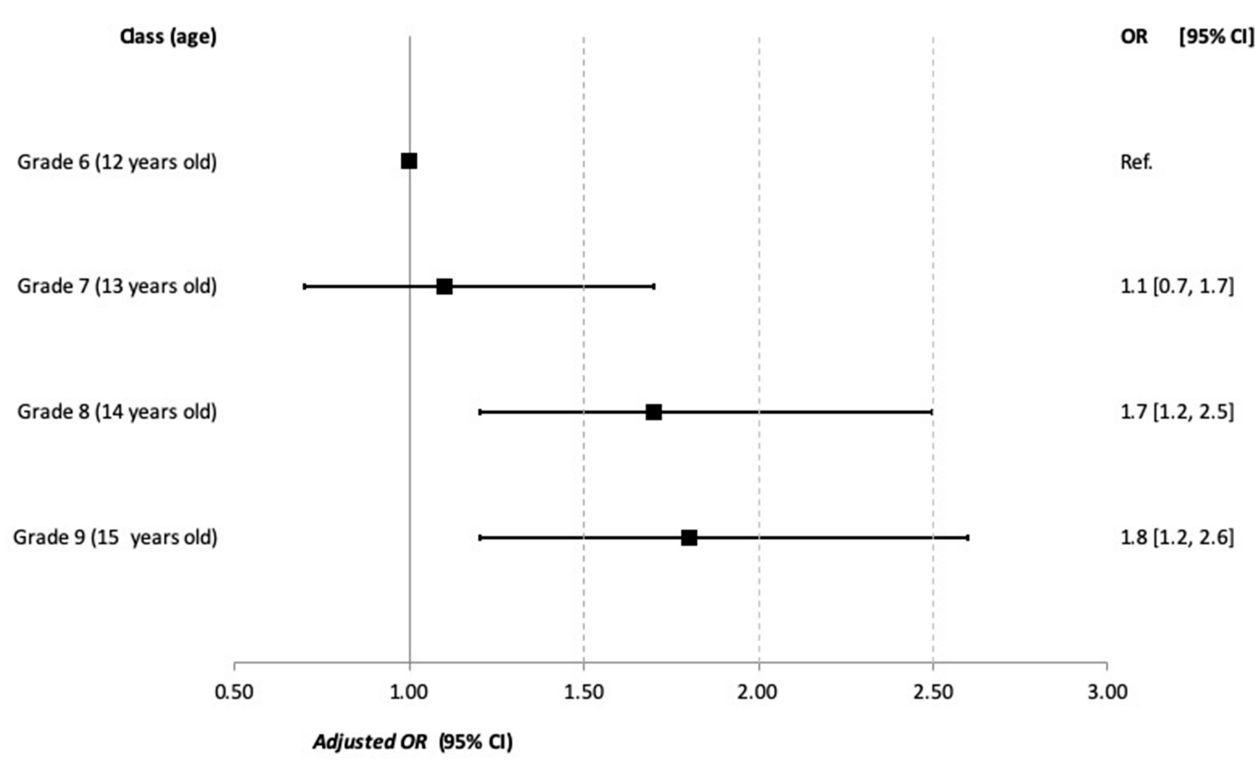

Figure I Adjusted odds ratio (OR) and $95 \%$ confidence intervals (Cl) for myopia (adjusted for sex) of children in higher grades as compared with the children in grade six (logistic regression analysis); Ref.: reference group.

Of the 1987 children examined, 83 (4.2\%) had presenting visual acuity worse than $6 / 12$ in the better eye, of whom $94 \%$ ( 78 of 83 children) were myopic. The total of children with presenting visual acuity of $6 / 12$ or worse in the better eye was 124 , of which $90.3 \%$ (112 of 124 children) were myopic (data not shown). Similarly, 307 children (15.5\%) had uncorrected visual acuity of 6/12 or worse in one or both eyes; these were then referred to examination for refraction diagnosis (data not shown). Table 2 summarizes presenting visual acuity in the better eye among myopic and total study children as well as the distribution of children by myopia category among myopic children. The proportion of moderate and severe visual impairment was 19.2\% among myopic children and $2.8 \%$ among total study children. Table 2 also indicates the distribution of myopia levels among myopic children. The majority of children had low myopia (93.6\%), whereas $6.4 \%$ of children presented with high myopia. A treatment gap of myopic children was observed, summary data of which is shown in Table 3. A total of 142 children ( $50.4 \%$ of myopic children) required myopia correction.

Summary characteristics of secondary school children in case (myopic children) and matched control (non-myopic children) groups are shown in Table 4. Case and control were matched exactly one-for-one by sex and grade. Hours spent per week performing various activities in case and matched control groups are shown in Table 5. Myopic children spent significantly more time indoors at home than did non-myopic children $(p<0.01)$. Specifically, myopic children spent more time reading and studying at home $(p=0.01)$, and less time watching television ( $p=0.01$ ), than did non-myopic children. Non-myopic children spent more total hours outdoors $(\mathrm{p}<0.01)$ and more hours performing outdoor sports activities $(\mathrm{p}=0.01)$ than did myopic children.

Table 2 Presenting Visual Acuity and Myopia Categories Among Myopic and Total Study Children

\begin{tabular}{|l|l|l|}
\hline Category & Myopic Children (n=282) N (\%) & All Children (n=I 987) N (\%) \\
\hline Vision category (distance presenting visual acuity in the better eye) & & \\
$\quad$ Normal $(6 / 6-6 / / 2)$ & $204(72.3)$ & $1904(95.8)$ \\
Mild visual impairment (<6/I2-6//8) & $24(8.5)$ & $28(1.4)$ \\
Moderate visual impairment $(<6 / / 8-6 / 60)$ & $49(17.4)$ & $50(2.5)$ \\
Severe visual impairment (<6/60) & $5(1.8)$ & $5(0.3)$ \\
\hline Myopia category & & NA \\
Low (-0.5 D to <-5.0 D) & $264(93.6)$ & NA \\
High ( $\leq-5.0$ D) & $18(6.4)$ & \\
\hline
\end{tabular}


Table 3 Summary of Treatment Gap for Myopic Children

\begin{tabular}{|l|l|}
\hline & $\begin{array}{l}\text { Myopic Children } \\
\text { (n=282) N (\%) }\end{array}$ \\
\hline Myopic children without spectacles & $125(44.3)$ \\
\hline $\begin{array}{l}\text { Myopic children wearing under- } \\
\text { corrected spectacles }\end{array}$ & $17(6.0)$ \\
\hline $\begin{array}{l}\text { Total myopic children in need of } \\
\text { corrected spectacles }\end{array}$ & $142(50.4)$ \\
\hline
\end{tabular}

Table 4 Characteristics of Secondary School Children in Case and Matched Control Groups in the Study

\begin{tabular}{|c|c|c|}
\hline & Case $(n=265)$ & Control (265) \\
\hline & \multicolumn{2}{|l|}{ n (\%) } \\
\hline \multicolumn{3}{|l|}{ Sex } \\
\hline Female & $108(40.8)$ & $108(40.8)$ \\
\hline Male & 157 (59.3) & 157 (59.3) \\
\hline \multicolumn{3}{|l|}{ Grade (age) } \\
\hline 6 (12 years old) & $54(20.4)$ & $54(20.4)$ \\
\hline 7 (13 years old) & $53(20.0)$ & $53(20.0)$ \\
\hline 8 (14 years old) & $80(30.2)$ & $80(30.2)$ \\
\hline 9 (15 years old) & $78(29.4)$ & $78(29.4)$ \\
\hline
\end{tabular}

Notes: Case: myopic children; control: non-myopic children.

Table 5 Summary of Hours Spent per Week Among in Case and Matched Control Secondary School Children Groups

\begin{tabular}{|l|l|l|l|}
\hline \multirow{2}{*}{$\begin{array}{l}\text { Activities (Hours per } \\
\text { Week) }\end{array}$} & \multicolumn{2}{l|}{$\begin{array}{l}\text { Case } \\
(\mathbf{n}=265)\end{array}$} & \multicolumn{2}{l|}{$\begin{array}{l}\text { Control } \\
\mathbf{( 2 6 5 )}\end{array}$} & \multirow{2}{*}{ p-value } \\
\cline { 2 - 3 } & \multicolumn{2}{|l|}{ Mean (SD) } & \\
\hline Sleeping & $61.7(6.5)$ & $61.7(6.1)$ & 0.95 \\
\hline Indoors at home & $61.1(8.1)$ & $58.7(7.9)$ & $<0.01$ \\
Reading or studying & $21.1(9.1)$ & $19.2(8.4)$ & 0.01 \\
Using computer & $10.6(7.6)$ & $10.3(8.1)$ & 0.70 \\
Watching television & $6.9(5.7)$ & $8.2(6.8)$ & 0.01 \\
\hline Outdoors & $12.1(4.6)$ & $14.1(5.8)$ & $<0.01$ \\
Sports activity & $8.9(4.4)$ & $9.9(5.1)$ & 0.01 \\
\hline
\end{tabular}

Notes: Case: myopic children; control: non-myopic children.

The results of univariate and multivariate logistic regression analyses regarding myopia and potential associated factors are shown in Table 6. Higher myopia prevalence was associated with having a mother with a college/university education $(\mathrm{OR}=2.5,95 \% \mathrm{CI}=1.2-5.3)$, parents who wore spectacles $(\mathrm{OR}=2.0,95 \% \mathrm{CI}=1.1-3.8)$, distance from near work less than $30 \mathrm{~cm}(\mathrm{OR}=5.2,95 \% \mathrm{CI}=3.5-7.9)$, and no taking breaks after 30 minutes of continued reading $(\mathrm{OR}=1.6$,
95\% CI $=1.1-2.5)$ were identified. However, there were inverse associations with myopia for children belonging to the wealthiest households $(\mathrm{OR}=0.2,95 \% \mathrm{CI}=0.1-0.5)$ and time spent performing outdoor activity $(\mathrm{OR}=0.6,95 \%$ $\mathrm{CI}=0.4-0.9)$.

The predicted probability of the presence of myopia and the marginal effect of hours per week spent performing outdoor activities, adjusted for the mother's education level, history of parental myopia, number of hours per week reading or studying, using computers, and watching television, are shown in Figure 2. The probability of developing myopia tended to decrease as the number of hours per week spent performing outdoor activities increased. The probability of developing myopia decreased to $50 \%$ if the children played outdoors 14 hours per week (two hours per day) and to $40 \%$ if the children played outdoors 21 hours per week (three hours per day).

\section{Discussion}

This study was conducted in a rural area that is rapidly urbanizing. We found that a considerable prevalence of secondary school children suffered from myopia, and that prevalence increased with school grade level. A shorter near work distance and taking fewer breaks while reading was associated with increased myopia, whereas increased time spent outdoors was associated with decreased myopia. This study provides evidence about the status of myopia in rural areas that are undergoing rapid urbanization and confirms the existence of factors that are associated with myopia, and may thus provide direction with regards to appropriate policies for prevention of schoolage myopia in Vietnam.

A recent study concerning eye health was conducted by the Mekong Development Research Institute with the support of The Fred Hollows Foundation, ${ }^{15}$ in which the study team focused on refractive error but did not report specifically about myopia. Moreover, as that study measured visual acuity of children without cycloplegia, the accuracy of refractive error prevalence may be limited. ${ }^{15}$ In the current study, we measured visual acuity after cycloplegia, thus ensuring myopia prevalence estimation accuracy. In our study, the average myopia prevalence was estimated to be $14.2 \%$, which is lower than the average prevalence of myopic in both rural and urban areas in a study conducted by Paudel et al in Ba RiaVung Tau, Vietnam (20.2\%). ${ }^{18}$ When only rural areas are considered; however, prevalence of myopia in that study $(16.3 \%)$ was slightly higher than that of our study.$^{18}$ Previous studies conducted in China, ${ }^{23-29}$ South Korea, ${ }^{30}$ Indonesia, ${ }^{31}$ 
Table 6 Myopia and Associated Factors: Univariate and Multivariate Logistic Regression Analyses

\begin{tabular}{|c|c|c|c|c|}
\hline & Case $(n=265) N(\%)$ & Control (265) N (\%) & $\begin{array}{l}\text { Univariate OR } \\
(95 \% \mathrm{Cl})\end{array}$ & $\begin{array}{l}\text { Adjusted OR } \\
(95 \% \mathrm{CI})\end{array}$ \\
\hline \multicolumn{5}{|l|}{ Mother's education } \\
\hline Primary school or less & $43(16.2)$ & $52(19.6)$ & 1 & 1 \\
\hline Secondary school & $86(32.5)$ & $88(33.2)$ & $1.2(0.7-2.0)$ & $1.4(0.8-2.6)$ \\
\hline High school & $57(21.5)$ & $57(21.5)$ & $1.2(0.7-2.1)$ & I.4 (0.7-2.7) \\
\hline College/university & $79(29.8)$ & $68(25.7)$ & $1.4(0.8-2.4)$ & $2.5^{* *}(I .2-5.3)$ \\
\hline \multicolumn{5}{|l|}{ Socioeconomic status (quintile) } \\
\hline Poorest & $65(24.3)$ & $54(20.4)$ & I & I \\
\hline Poor & $4 \mid(15.5)$ & $52(19.6)$ & $0.7(0.4-1.1)$ & $0.6(0.3-1.2)$ \\
\hline Middle & $53(20.0)$ & $53(20.0)$ & $0.8(0.5-1.4)$ & $0.6(0.4-1.2)$ \\
\hline Rich & $80(30.2)$ & $53(20.0)$ & $1.3(0.8-2.1)$ & $0.9(0.5-1.7)$ \\
\hline Richest & $26(9.8)$ & $53(20.0)$ & $0.4^{* *}(0.2-0.7)$ & $0.2 * * *(0.1-0.5)$ \\
\hline \multicolumn{5}{|l|}{ Either parent wearing spectacles } \\
\hline No & $227(85.7)$ & 243 (9I.7) & I & 1 \\
\hline Yes & $38(14.3)$ & $22(8.3)$ & $1.8^{*}(1.1-3.2)$ & $2.0 *(I . I-3.8)$ \\
\hline \multicolumn{5}{|l|}{ No. of hours per week reading or studying indoors } \\
\hline$<21$ hours & $133(50.2)$ & $160(60.4)$ & I & 1 \\
\hline$\geq 2$ I hours & $132(49.8)$ & $105(39.6)$ & $1.5 * *(1.1-2.1)$ & $1.4(0.9-2.0)$ \\
\hline \multicolumn{5}{|l|}{ No. of hours per week using computers } \\
\hline$<7$ hours & $92(34.7)$ & $109(4 I . I)$ & 1 & $\mathrm{I}$ \\
\hline$\geq 7$ hours & $173(65.3)$ & $156(58.9)$ & $1.3(0.9-1.9)$ & $1.4(0.9-2.1)$ \\
\hline \multicolumn{5}{|l|}{ No. of hours per week watching television } \\
\hline$<7$ hours & $147(55.5)$ & $138(52.1)$ & 1 & I \\
\hline$\geq 7$ hours & II 8 (44.5) & $127(47.9)$ & $0.9(0.6-1.2)$ & $0.8(0.6-1.2)$ \\
\hline \multicolumn{5}{|l|}{ No. of hours per week outdoor activities } \\
\hline$<14$ hours & $178(67.2)$ & $142(53.6)$ & I & 1 \\
\hline$\geq 14$ hours & $87(32.8)$ & $123(46.4)$ & $0.6 *(0.4-0.8)$ & $0.6 * * *(0.4-0.9)$ \\
\hline \multicolumn{5}{|l|}{ Distance from near work (cm) } \\
\hline$\geq 30 \mathrm{~cm}$ & III (4I.9) & $206(77.7)$ & I & I \\
\hline$<30 \mathrm{~cm}$ & $154(58.1)$ & $59(22.3)$ & $4.8^{* * *}(3.3-7.1)$ & $5.2 * * *(3.5-7.9)$ \\
\hline \multicolumn{5}{|l|}{ Takes breaks after 30 minutes of continuous reading } \\
\hline Yes & $162(6 \mid . I)$ & $187(70.6)$ & 1 & 1 \\
\hline No & $103(38.9)$ & $78(29.4)$ & $1.5^{*}(1.1-2.2)$ & $1.6 *(1.1-2.5)$ \\
\hline
\end{tabular}

Notes: $*<0.05, * *<0.01, * * *<0.001$; case: myopic children; control: non-myopic children.

Abbreviation: $\mathrm{Cl}$, confidence interval.

Australia, ${ }^{32}$ France, ${ }^{33}$ and the USA $^{34}$ reported higher prevalence of myopia, while studies conducted in India, ${ }^{35}$ Saudi Arabia, ${ }^{36-38}$ Brazil $^{39}$ and Paraguay ${ }^{40}$ reported lower prevalence than that reported presently. These differences may occur due to differences in subject ages, cut-off thresholds for myopia diagnosis, or methods of measurement (cycloplegia or noncycloplegia). Within countries, the prevalence of myopia may also vary between different areas. ${ }^{41}$ In the present study, we conducted only research in a rural area, and our results may be lower than those of studies conducted in urban areas.
We reported that prevalence increased with school grade level, and that differences in prevalence were small between grades six and seven (10.5\% vs $11.8 \%$ ), but increased with grade level in each comparison group $(17.1 \%$ and $17.7 \%$ in grades eight and nine, respectively). Increasing pressure for achieving high educational attainment may increase the prevalence of myopia in children. In the secondary school system in Vietnam, grades eight and nine are considered upper-level grades, after which students are required to pass an exam to advance to high school. An associated increase in studying 


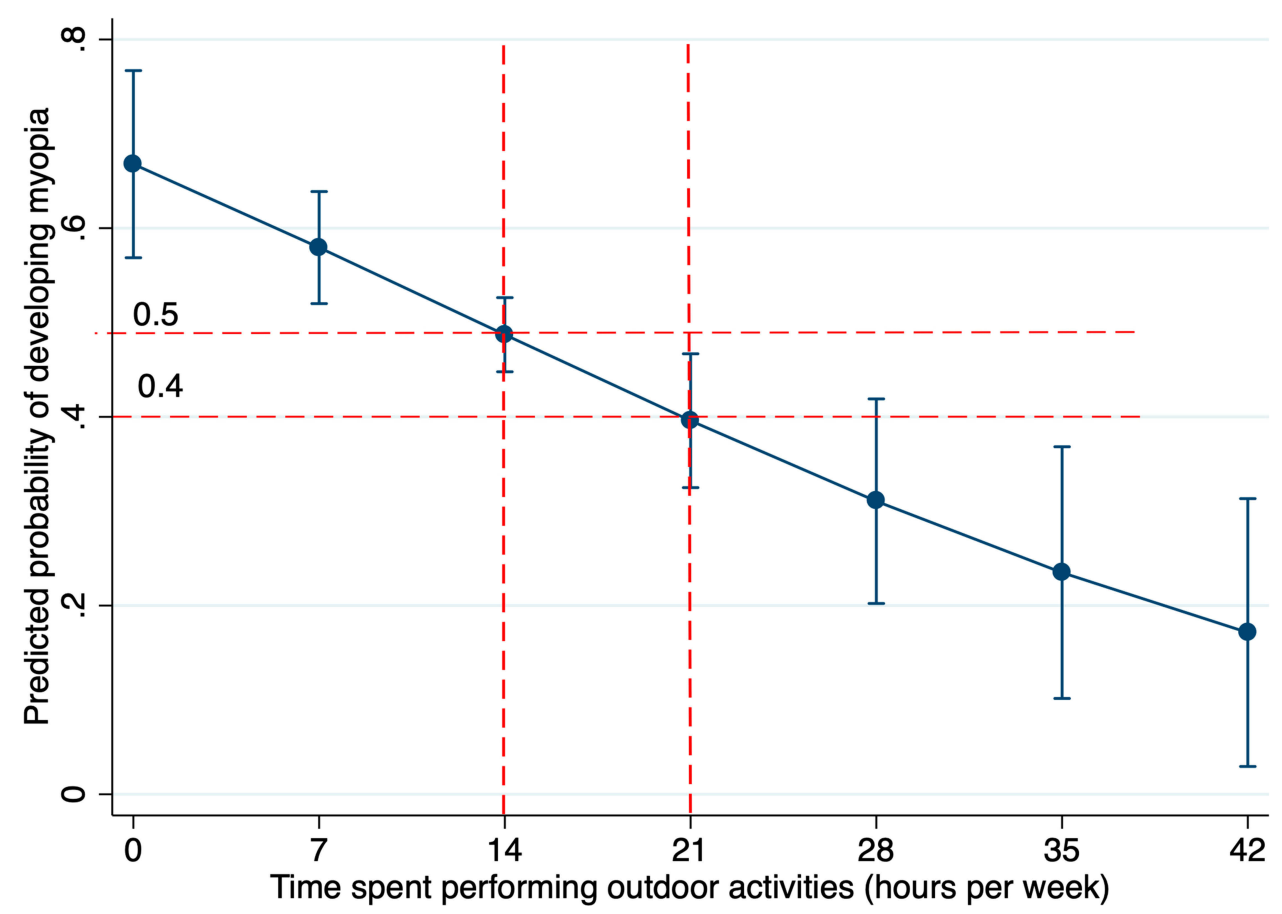

Figure 2 Predicted probability of myopia and marginal effect of hours per week of children spending on outdoor activities (adjusted for mother's educational attainment, history of parental myopia, number of hours per week reading or studying, using computer, and watching television).

time likely explains why the prevalence of myopia sharply increased in the higher two grades. This result is similar to those of other studies, which reported that the likelihood of myopia increased with age (or school grade). ${ }^{18,23,24,28,35,36,39,41}$ As such, developing reasonable and appropriate learning plans that include an emphasis on eye health may be a good solution to prevent school-age myopia and should be considered by education policymakers.

Our study showed that $4.2 \%$ of children had presenting visual acuity worse than $6 / 12$ in the better eye, and, if including children with presenting visual acuity of $6 / 12$, it reached to $6.2 \%$. This result is lower than that of studies in India and $\mathrm{Ba}$ Ria-Vung Tau, Vietnam. ${ }^{18,35,42}$ That the proportion of presenting visual acuity was relatively low in our study might be because our study was conducted in a rural area, whereas previous studies were conducted in urban areas or included urban areas. In our study, we found that the prevalence of untreated myopia was about $50.4 \%$ of all myopia cases. Importantly, this large percentage of children who did not wear spectacles among untreated myopic children showed that these children had not been previously diagnosed with myopia. Given the results of recent studies in Vietnam, ${ }^{15,18}$ the use of school staff for myopia screening may also be a good solution for the early detection of vision impairment among school children. Children suspected of suffering from myopia should be referred to hospitals for corrected myopia. Currently, providing spectacles were not reimbursed by the social health insurance in Vietnam. The uncorrected or under-corrected myopia will be reduced if the policy of social health insurance is changed.

We found that the prevalence of myopia was higher in girls than in boys, a result that was also noted in studies in China, ${ }^{23-25,28}$ India, ${ }^{35}$ and Saudi Arabia. ${ }^{36,37}$ In the study in Ba Ria-Vung Tau of Vietnam, Paudel et al also reported increased prevalence in girls as compared to boys. ${ }^{18}$ However, those authors did not report differences in terms of gender after multivariate regression analysis, although, to explain this gender difference, suggested that girls experienced more risk factors for the development of myopia than did boys, such as spending more time indoors reading and less time outdoors. ${ }^{18}$ According to observations and exchanges with teachers at the study schools, we also noted that girls tended to study harder and participate less in outdoor activities than did boys, which may explain the difference we observed.

Along with myopia status, an understanding of factors associated with the condition is also important. We found that time spent outdoors was significantly less in myopic children than in non-myopic children. Although a slight difference in average time was observed, these results are similar to those observed in Ba Ria-Vung Tau, Vietnam, ${ }^{18}$ Australia, ${ }^{43}$ China, ${ }^{23,44}$ and Brazil. ${ }^{45}$ Moreover, we performed marginal 
analysis to determine the relationship between time spent outdoors and myopia. To avoid confounding factors, we adjusted for mother's educational attainment, a history of parental myopia, and the number of hours per week spent reading or studying, using a computer, and watching television. We found that as the amount of time spent outdoors increases, the likelihood of myopia decreases significantly, such that if children spent two hours a day or more (equivalent to 14 hours per week or more), the possibility of developing myopia was $50 \%$ or less, and that if children spent three hours a day or more (equivalent to 21 hours per week or more), the possibility of developing myopia was reduced to $40 \%$ or less. Given that time spent studying and recreating requires a certain balance, spending two hours or more outdoors daily may be an appropriate recommendation for secondary school children. In a systematic review and meta-analysis conducted by Sherwin et al, it was suggested that an additional hour of time spent outdoors per week could reduce by $2 \%$ the odds of myopia. ${ }^{13}$

The mechanism for outdoor time with respect to myopia protection is currently unknown, and more studies are needed. However, there was a hypothesis about light received outdoors relating to the release of dopamine in the retina. The dopamine could make the suppression of axial elongation that helped to prevent the development of myopia. ${ }^{46}$ In addition, given that time spent performing outdoor activities is related to waking time spent indoors, ${ }^{13}$ increasing outdoor activity time will reduce indoor activity time. The results of our study showed that myopic children spent less time performing outdoor activities, and more time performing indoor activities than did non-myopic children. While our study was conducted in a rural area, current socioeconomic and urbanization changes in Vietnam may induce children to spend less time participating in outdoor activities. Thus, an emphasis on student participation in outdoor activities can be considered an appropriate goal for myopia prevention and one that should be considered by health care policymakers.

Several studies have reported associations between myopia and time spent on near work or studying. ${ }^{24,32,35}$ However, in our study, we only found a significant association between myopia and time spent on reading or studying indoors $(<21$ hours vs $\geq 21$ hours per week) in a univariate analysis; this association disappeared in the multivariable regression analysis. Our findings may differ from those of previous studies due to the use of different time period classification cut-off points regarding time spent on near work or studying. In a systematic review and meta-analysis, Huang et al indicated that several studies showed that near-work activities did not associate with an increase in the prevalence of myopia. ${ }^{14}$ Even so, near work activities should be observed and appropriate interventions implemented in order to reduce negative impacts with regards to the prevalence of myopia in children.

The factors of distance from near work and taking breaks after continuous reading can be altered by students. In our study, we found that a distance from near work of less than $30 \mathrm{~cm}$ and not taking breaks after 30 minutes of continuous reading were associated with increased myopia. This finding was consistent with those of studies from China ${ }^{25,47}$ and Australia. ${ }^{32}$ We also found that either parents' wearing of spectacles was associated with student myopia. In addition, children whose mothers had a college/university degree were more likely to develop myopia than children whose mothers had a primary school education or lower. Thus, in addition to genetic factors, it is likely that children with more highly educated mothers may be pressured to study more than are children with less highly educated mothers. Interestingly, we found an inverse association between myopia status and socioeconomic status. This result differed from that of the study in India, in which Saxena et al found that the prevalence of myopia was higher in children with higher socioeconomic status than in children with lower socioeconomic status. ${ }^{35}$ This could be explained by differing propensities towards eye health protection, although a larger sample size would be needed to understand this relationship.

There are several potential limitations to this study. As this study was conducted using a school-based approach, the estimated prevalence of myopia may be underestimated due to lack of knowledge regarding children who do not currently attend or have never attended school. Although non-response rates in this study were low, school participation rates by potential students may affect the estimation of the prevalence of myopia. Furthermore, children with prior knowledge of their own myopia or children with insecurities regarding their vision may not have participated. In addition, parental apprehensions regarding cycloplegic refraction may affect study participation rates. We also did not perform cycloplegic autorefraction on children with normal vision $(>6 / 12)$, something that may have resulted in an underestimation of myopia prevalence. While the choice of class as a clustering factor is considered optimal in terms of conducting a study in schools, and has been adjusted for by the design effect, there exists a possibility that the selected classes might not represent all classes in the study area. Finally, recall bias may also influence the results of the study, as children may inaccurately recall and estimate time spent per activity in a typical week day or weekend. 


\section{Conclusion}

Our study showed that the prevalence of myopia is considerable among secondary school children in rural areas of Vietnam. Moreover, the prevalence of myopia increased in higher grade levels, especially in grades eight and nine. The distance from near work and the taking of breaks after continuous reading can be altered to reduce the risk of myopia in children. In addition, increased outdoor activity was noted as a protective environmental factor against myopia in secondary school children. We recommend that future longitudinal studies focus specifically on the protective effects of outdoor activities on children to identify appropriate time thresholds for each age group of children.

\section{Data Sharing Statement}

The datasets used and/or analyzed during the current study are available from the corresponding author upon reasonable request.

\section{Ethics and Consent Statement}

The study proposal was approved by the ethics committee at the National Institute of Malariology, Parasitology, and Entomology (Hanoi, Vietnam; decision number 1141/QDVSR). The study followed the tenets of the Declaration of Helsinki for biomedical research. Permission to conduct the study was also received from the provincial and district training and education authority. All principals of selected schools agreed to participate in the study and to support the study team during data collection. Letters of invitation to participate in the study and informed consent documents were also sent to all parents or guardians. These documents included information explaining the study aims and objectives, possible adverse effects of dilatation, and the right to withdraw from the study at any time without consequences. A contact telephone number and email were included in the letters of invitation to participate in the study so that the parents or guardians could ask any questions related to the study. In cases where parents or guardians did not return the consent form, they were contacted by telephone to explain the study in more detail. Only children with a parent- or guardian-signed informed consent form were recruited.

\section{Acknowledgments}

The authors thank the children and their parents who participated in this study. We would like to acknowledge the Department of Health and the Department of Training and Education for their support in conducting this study. We would especially like to thank the health staff from the Quynh Lap National Leprosy Dermatology Hospital for their contribution to data collection.

\section{Funding}

No funding or sponsorship was received for this study or publication of this article. The article processing charges were funded by the authors.

\section{Disclosure}

$\mathrm{Vu}$ Duy Kien was employed with OnCare Medical Technology Company Limited during the study. The authors report no conflicts of interest in this work.

\section{References}

1. Morgan IG, French AN, Ashby RS, et al. The epidemics of myopia: aetiology and prevention. Prog Retin Eye Res. 2018;62:134-149. doi:10.1016/j.preteyeres.2017.09.004

2. Walline JJ. Myopia control: a review. Eye Contact Lens. 2016;42 (1):3-8. doi:10.1097/ICL.0000000000000207

3. Tay SA, Farzavandi S, Tan D. Interventions to reduce myopia progression in children. Strabismus. 2017;25(1):23-32. doi:10.1080/ 09273972.2016.1276940

4. Naidoo KS, Fricke TR, Frick KD, et al. Potential lost productivity resulting from the global burden of myopia: systematic review, meta-analysis, and modeling. Ophthalmology. 2019;126(3):338-346. doi:10.1016/j.ophtha.2018.10.029

5. Morgan IG, Ohno-Matsui K, Saw SM. Myopia. Lancet. 2012;379 (9827):1739-1748. doi:10.1016/S0140-6736(12)60272-4

6. Holden BA, Fricke TR, Wilson DA, et al. Global prevalence of myopia and high myopia and temporal trends from 2000 through 2050. Ophthalmology. 2016;123(5):1036-1042. doi:10.1016/j. ophtha.2016.01.006

7. Goldschmidt E, Jacobsen N. Genetic and environmental effects on myopia development and progression. Eye (Lond). 2014;28 (2):126-133. doi:10.1038/eye.2013.254

8. Rose KA, French AN, Morgan IG, Factors E. Myopia: paradoxes and prospects for prevention. Asia Pac J Ophthalmol (Phila). 2016;5 (6):403-410. doi:10.1097/APO.0000000000000233

9. Verhoeven VJ, Hysi PG, Wojciechowski R, et al. Genome-wide meta-analyses of multiancestry cohorts identify multiple new susceptibility loci for refractive error and myopia. Nat Genet. 2013;45 (3):314-318. doi:10.1038/ng.2554

10. Fan Q, Wojciechowski R, Kamran Ikram M, et al. Education influences the association between genetic variants and refractive error: a meta-analysis of five Singapore studies. (1460-2083 (Electronic)). Hum Mol Genet. 2014;23(2):546-554. doi:10.1093/hmg/ddt431

11. Pan CW, Qian DJ, Saw SM. Time outdoors, blood vitamin D status and myopia: a review. Photochem Photobiol Sci. 2017;16 (3):426-432. doi:10.1039/C6PP00292G

12. Leo SW. Scientific bureau of World Society of Paediatric O, strabismus. Current approaches to myopia control. Curr Opin Ophthalmol. 2017;28(3):267-275. doi:10.1097/ICU.0000000000000367

13. Sherwin JC, Reacher MH, Keogh RH, Khawaja AP, Mackey DA, Foster PJ. The association between time spent outdoors and myopia in children and adolescents: a systematic review and meta-analysis. Ophthalmology. 2012;119(10):2141-2151. doi:10.1016/j.ophtha. 2012.04.020 
14. Huang H-M, Chang DS-T, Wu P-C. The association between near work activities and myopia in children - a systematic review and meta-analysis. PLoS One. 2015;10(10).

15. Mekong Development Research Institute. Eye Health Among School Children in Vietnam: Prevalence of Refractive Errors, Accuracy of School-Based Screening, and KAPs Among Students, Parents, and School Staff. A Fred Hollows Foundation Research Report. Hanoi; 2017.

16. Government of Vietnam. Decision to approve the National Plan for blindness prevention and eye care towards 2020 and vision 2030 2016. Available from: http://datafilesbk.chinhphu.vn/file-remote-v2 /DownloadServlet?filePath=vbpq/2017/01/2560.signed.pdf. Accessed January 26, 2020.

17. Limburg H, Gilbert C, Hon DN, Dung NC, Hoang TH. Prevalence and causes of blindness in children in Vietnam. Ophthalmology. 2012;119(2):355-361. doi:10.1016/j.ophtha.2011.07.037

18. Paudel P, Ramson P, Naduvilath T, et al. Prevalence of vision impairment and refractive error in school children in Ba Ria - Vung Tau province, Vietnam. Clin Exp Ophthalmol. 2014;42(3):217-226. doi:10.1111/ceo. 12273

19. World Health Organization. Assessment of the prevalence of visual impairment attributable to refractive error or other causes in school children. Protocol and manual Ginebra: World Health Organization; 2007.

20. Wanga SK, Lemeshow S; Organization WH. Sample Size Determination in Health Studies: A Practical Manual; 1991.

21. World Health Organization. The Impact of Myopia and High Myopia. Geneva, Switzerland: World Health Organization; 2016.

22. Vyas S, Kumaranayake L. Constructing socio-economic status indices: how to use principal components analysis. Health Policy Plan. 2006;21(6):459-468. doi:10.1093/heapol/czl029

23. Guo K, Yang DY, Wang Y, et al. Prevalence of myopia in schoolchildren in Ejina: the Gobi desert children eye study. Invest Ophthalmol Vis Sci. 2015;56(3):1769-1774. doi:10.1167/iovs.1415737

24. Guo L, Yang J, Mai J, et al. Prevalence and associated factors of myopia among primary and middle school-aged students: a school-based study in Guangzhou. Eye (Lond). 2016;30(6):796-804. doi:10.1038/eye.2016.39

25. Li Y, Liu J, Qi P. The increasing prevalence of myopia in junior high school students in the Haidian District of Beijing, China: a 10-year population-based survey. BMC Ophthalmol. 2017;17(1):88 doi:10.1186/s12886-017-0483-6

26. Lin Z, Gao TY, Vasudevan B, et al. Generational difference of refractive error and risk factors in the Handan Offspring Myopia Study. Invest Ophthalmol Vis Sci. 2014;55(9):5711-5717. doi:10. 1167/iovs.13-13693

27. Pan CW, Wu RK, Liu H, Li J, Zhong H. Types of lamp for homework and myopia among Chinese school-aged children. Ophthalmic Epidemiol. 2018;25(3):250-256. doi:10.1080/09286586.2017.14 20204

28. Wu JF, Bi HS, Wang SM, et al. Refractive error, visual acuity and causes of vision loss in children in Shandong, China. The Shandong Children Eye Study. PLoS One. 2013;8(12):e82763. doi:10.1371/ journal.pone.0082763

29. Zhou WJ, Zhang YY, Li H, et al. Five-year progression of refractive errors and incidence of Myopia in school-aged children in Western China. $J$ Epidemiol. 2016;26(7):386-395. doi:10.2188/jea.JE201 40258

30. Rim TH, Kim SH, Lim KH, et al. Refractive errors in Koreans: the Korea National Health and Nutrition Examination Survey 2008-2012. Korean J Ophthalmol. 2016;30(3):214-224. doi:10.33 41/kjo.2016.30.3.214
31. Mahayana IT, Indrawati SG, Pawiroranu S. The prevalence of uncorrected refractive error in urban, suburban, exurban and rural primary school children in Indonesian population. Int J Ophthalmol. 2017;10 (11):1771-1776. doi:10.18240/ijo.2017.11.21

32. French AN, Morgan IG, Mitchell P, Rose KA. Risk factors for incident myopia in Australian schoolchildren: the Sydney adolescent vascular and eye study. Ophthalmology. 2013;120(10):2100-2108. doi:10.1016/j.ophtha.2013.02.035

33. Matamoros E, Ingrand P, Pelen F, et al. Prevalence of myopia in France: a cross-sectional analysis. Medicine (Baltimore). 2015;94 (45):e1976. doi:10.1097/MD.0000000000001976

34. Theophanous C, Modjtahedi BS, Batech M, Marlin DS, Luong TQ, Fong DS. Myopia prevalence and risk factors in children. Clin Ophthalmol. 2018;12:1581-1587. doi:10.2147/OPTH.S164641

35. Saxena R, Vashist P, Tandon R, et al. Prevalence of myopia and its risk factors in urban school children in Delhi: the North India Myopia Study (NIM study). PLoS One. 2015;10(2):e0117349. doi:10.1371/ journal.pone. 0117349

36. Al Wadaani FA, Amin TT, Ali A, Khan AR. Prevalence and pattern of refractive errors among primary school children in Al Hassa, Saudi Arabia. Glob J Health Sci. 2012;5(1):125-134. doi:10.5539/gjhs. v5n 1 p 125

37. Aldebasi YH. Prevalence of correctable visual impairment in primary school children in Qassim Province, Saudi Arabia. J Optom. 2014;7 (3):168-176. doi:10.1016/j.optom.2014.02.001

38. Alrahili NHR, Jadidy ES, Alahmadi BSH, et al. Prevalence of uncorrected refractive errors among children aged 3-10 years in western Saudi Arabia. Saudi Med J. 2017;38(8):804-810. doi:10.15537/ smj.2017.8.20412

39. Lira RP, Arieta CE, Passos TH, et al. Distribution of ocular component measures and refraction in Brazilian School Children. Ophthalmic Epidemiol. 2017;24(1):29-35. doi:10.1080/09286586. 2016.1254249

40. Carter MJ, Lansingh VC, Schacht G, Río Del Amo M, Scalamogna M, France TD. Visual acuity and refraction by age for children of three different ethnic groups in Paraguay. Arq Bras Oftalmol. 2013;76 (2):94-97. doi:10.1590/S0004-27492013000200008

41. Grzybowski A, Kanclerz P, Tsubota K, Lanca C, Saw SM. A review on the epidemiology of myopia in school children worldwide. $B M C$ Ophthalmol. 2020;20(1):27. doi:10.1186/s12886-019-1220-0

42. Atowa UC, Hansraj R, Wajuihian SO. Visual problems: a review of prevalence studies on visual impairment in school-age children. Int J Ophthalmol. 2019;12(6):1037.

43. Rose KA, Morgan IG, Ip J, et al. Outdoor activity reduces the prevalence of myopia in children. Ophthalmology. 2008;115 (8):1279-1285. doi:10.1016/j.ophtha.2007.12.019

44. He M, Xiang F, Zeng Y, et al. Effect of time spent outdoors at school on the development of myopia among children in China: a randomized clinical trial. JAMA. 2015;314(11):1142-1148. doi:10.1001/jama.2015.10803

45. Moraes FI, Moraes MI, de Camargo Pomepo J, Veronese LRM, Scott I, Silva JP. Visual impairment and myopia in Brazilian children: a population-based study. Optom Vis Sci. 2013;90(3):223-227. doi:10.1097/OPX.0b013e31828197fd

46. McCarthy C, Megaw P, Devadas M, Morgan I. Dopaminergic agents affect the ability of brief periods of normal vision to prevent form-deprivation myopia. Exp Eye Res. 2007;84(1):100-107. doi:10.1016/j.exer.2006.09.018

47. Lee C-W, Fang S-Y, Tsai D-C, et al. Prevalence and association of refractive anisometropia with near work habits among young schoolchildren: the evidence from a population-based study. PLoS One. 2017;12(3). 


\section{Publish your work in this journal}

Clinical Ophthalmology is an international, peer-reviewed journal covering all subspecialties within ophthalmology. Key topics include: Optometry; Visual science; Pharmacology and drug therapy in eye diseases; Basic Sciences; Primary and Secondary eye care; Patient Safety and Quality of Care Improvements. This journal is indexed on PubMed
Central and CAS, and is the official journal of The Society of Clinical Ophthalmology (SCO). The manuscript management system is completely online and includes a very quick and fair peer-review system, which is all easy to use. Visit http://www.dovepress.com testimonials.php to read real quotes from published authors. 